\title{
The Dependence of Onset and Duration of Sleep on the Circadian Rhythm of Rectal Temperature*
}

\author{
Jürgen Zulley, Rütger Wever, and Jürgen Aschoff \\ Max-Planck-Institut für Verhaltensphysiologie, Seewiesen and Andechs, \\ D-8138 Andechs, Federal Republic of Germany
}

\begin{abstract}
The sleep-wake cycle and the circadian rhythm of rectal temperature were recorded in subjects who lived singly in an isolation unit. In 10 subjects, the freerunning rhythms remained internally synchronized, 10 other subjects showed internal desynchronization. Times of onset and end of bedrest ("sleep") were determined in each cycle and referred to the phase of the temperature rhythm. In the synchronized subjects, onset of sleep occurred, on the average, $1.34 \mathrm{~h}$ before the minimum of temperature, and end of sleep $6.94 \mathrm{~h}$ thereafter, with narrow distributions. The desynchronized subjects had a broad bimodal distribution of sleep onsets (peaks 6.3 and $1.3 \mathrm{~h}$ before the minimum); the duration of sleep varied between more than $15 \mathrm{~h}$ when sleep began about $10 \mathrm{~h}$ before the temperature minimum, and less than $4 \mathrm{~h}$ when sleep began several hours after the minimum. The dependence of sleep duration on body temperature is interpreted as a continuing action of the coupling forces between the two rhythms after mutual synchronization is lost.
\end{abstract}

Key words: Circadian rhythms - Sleep - Body temperature - Internal phase-relationship

\section{Introduction}

In the human organism, most physiological functions are subject to periodic changes which are in synchrony with the sleep-wake cycle and whose period corresponds to the 24-h day. This periodicity persists in subjects who live in isolation units without any external time cues, but the frequency of the then freerunning circadian rhythms slightly deviates from that of the earth's rotation. Under those conditions, the sleepwake cycle and e.g. the rhythm of rectal temperature frequently show the same period of about $25 \mathrm{~h}$ and keep a stable phase-relationship to each other, a state which is called "internal synchronization". However, in about $30 \%$ of such experiments the coupling between the two functions has been found to be instable, resulting in different frequencies of the two freerunning rhythms and, hence, in a continuous variation of the phase-relationship between the sleep-wake cycle and the rhythm of rectal temperature (Aschoff et al. 1967a). In such a state of "internal desynchronization" the coupling forces, although insufficient for mutual synchronization, still exert an influence on both rhythms. Due to this interaction,

Send offprint requests to J. Aschoff at the above address

* Dedicated to Prof. Dr. Rudolf Thauer on the occasion of his 75 th birthday the sleep-wake cycle and the rhythm of rectal temperature are subject to periodic variations. In this report, the dependence is discussed of sleep characteristics on the phase of the rhythm of rectal temperature.

\section{Methods}

Twenty young volunteers (15 males, 5 females; age 20-61 years) lived singly in an isolation unit for at least 4 weeks. The subjects had no information about the time of day, and were either allowed to turn the lights off during the sleep episodes of their selfselected activity-rest cycle or were exposed to constant illumination. Body temperature was recorded continuously by a rectal probe, and various activities of each subject were monitored by signals elicited through a switch board. As an approximate measure for the duration of sleep, the interval was taken between a signal given by the subject when he decided to go to sleep (turning off his bedside reading lamp), and a signal given at the time of awakening. Further details of the experimental procedure have been described by Wever (1979).

The twenty subjects whose data are analyzed here, represent a selection from a larger sample of experiments all performed under similar conditons. The selection was made in accordance with the two possible states of a freerunning rhythm: 10 subjects with together 205 sleep episodes remained internally synchronized throughout the experiment, the other 10 subjects with 206 sleep episodes showed internal desynchronization.

In an additional subject, sleep was polygraphically recorded by measuring EEG, EOG and EMG. This subject was exposed to an artificial light-dark cycle the period of which was $23 \mathrm{~h}$ in the first part and $26 \mathrm{~h}$ in the second part of the experiment.

\section{Results}

A representative example of a freerunning $x h y t h m$ is provided in Fig. 1. Consecutive sleep episodes are indicated by horizontal bars, the minima of rectal temperature by triangles. The upper half of the diagram demonstrates the state of internal synchronization, the lower half the state of internal desynchronization. During synchronization both rhythms had the same mean period of $25.7 \mathrm{~h}$, and the mean phase-angle difference between temperature minimum and onset of sleep was $-2.1 \mathrm{~h}$. After internal desynchronization had occurred on day 14 , the sleep-wake cycle assumed a mean period of $33.4 \mathrm{~h}$ while the rhythm of rectal temperature continued to freerun with a mean period of $25.1 \mathrm{~h}$. As a result of this, consecutive 


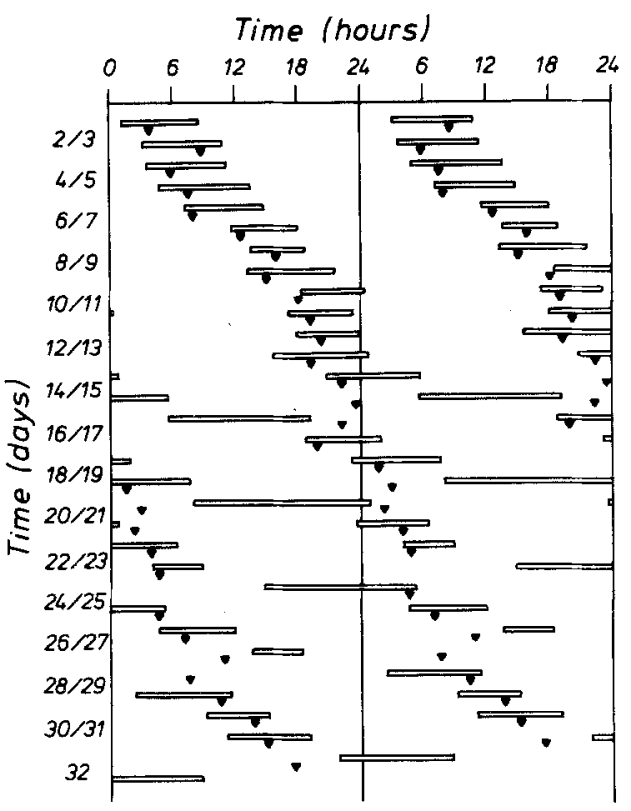

Fig. 1. Consecutive sleep episodes (white bars: bedrest) and minima of rectal temperature (triangles) of a subject living alone in the isolation unit. Double plot
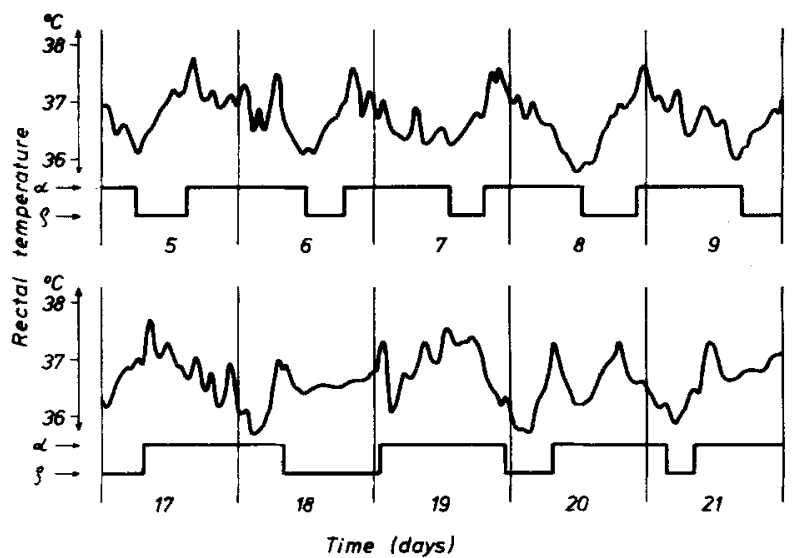

Fig. 2. Rectal temperature and sleep-wake cycle ( $\alpha$ : wakefulness; $\varrho$ bedrest) recorded in an isolated subject during internal synchronization (above) and internal desynchronization (below). Two sections of the experiment shown in Fig. 1 (cf. the number of days)

minima of temperature coincided with different phases of the sleep-wake cycle. It is furthermore obvious that duration of sleep was rather constant during internal synchronization, but had an extreme variation between short and long sleep episodes during internal desynchronization. From each of the two states, 5 days of the original records are reproduced in Fig. 2. During internal synchronization (upper two curves), the minima of temperature were always close to the beginning of sleep as it is well known from all freerunning internally synchronized rhythms (Aschoff et al. 1967b); during desynchronization, consecutive minima occurred at different phases of the sleep-wake cycle, and duration of sleep varied considerably.

For the following analysis, the minimum of rectal temperature has been determined in each single cycle and is used as a reference phase further on. The general relationship

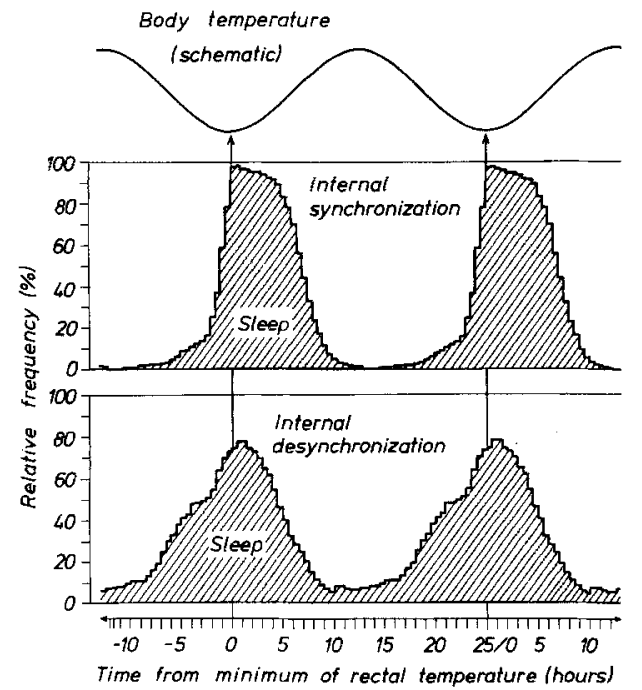

Fig. 3. Frequency of sleep drawn with reference to the phase of the rhythm of rectal temperature. Data from singly isolated subjects with internal synchronization ( $n=10 ; 205$ sleep episodes) and internal desynchronization ( $n=10 ; 206$ sleep episodes). Double plot

between sleep and the rhythm of rectal temperature is illustrated in Fig. 3. For the internally synchronized subjects, nearly $100 \%$ were asleep at the time of their temperature minima and a few hours thereafter, and none was asleep at the time of high temperatures. During internal desynchronization, sleep did not occur at random with regard to the temperature rhythm as one might have expected from Fig. 1, but had a distribution not too different from that of the internally synchronized subjects: close to $80 \%$ were asleep at the temperature minima, and only about $10 \%$ at the time of the maxima.

From the histograms in Fig. 3 it can be concluded that the coupling to the rhythm of rectal temperature is of different precision for onset and for end of sleep during internal synchronization, and differs during synchronization from the precision during desynchronization. This is more clearly shown in Fig. 4. In the internally synchronized subjects, onset of sleep occurs, on the average, $1.34 \mathrm{~h}$ before temperature minimum, with a standard deviation of only $\pm 1.97 \mathrm{~h}$ around that mean; end of sleep occurs $6.94 \pm 2.01 \mathrm{~h}$ after the minimum. In contrast to these unimodal distributions for onset and end of sleep during internal synchronization, onset of sleep has a bimodal distribution during internal desynchronization, the two peaks occurring at about 1.3 and $6.3 \mathrm{~h}$ before the temperature minimum; end of sleep has an unimodal distribution which is broader than that of the internally synchronized subjects and has an earlier mean (5.10 $\pm 2.21 \mathrm{~h}$ after the temperature minimum). It further follows from the right histograms of Fig. 4 that, during internal desynchronization, there must have been long and short sleep episodes depending on when in the temperature rhythm sleep occurred. In other words: duration of sleep seems to be a function of the phase of the temperature rhythm. This relationship is documented in Fig. 5. Sleep is longest when onset of sleep occurs about $8 \mathrm{~h}$ prior to the temperature minimum, i.e. at the time of high and decreasing temperatures; sleep becomes shorter with progressively later onsets of 


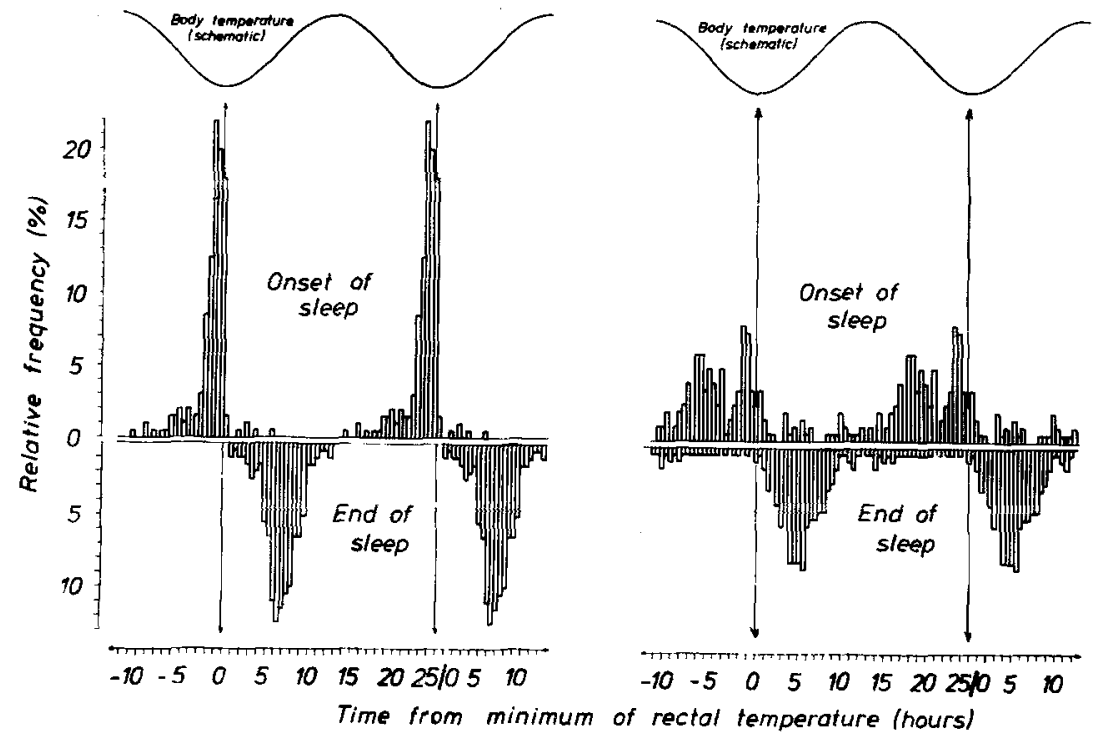

Fig. 4

Distribution of onset and end of sleep in reference to the phase of the rhythm of rectal temperature, Data from singly isolated subjects with internal synchronization (205 sleep episodes) and desynchronization (206 sleep episodes), respectively. Double plots

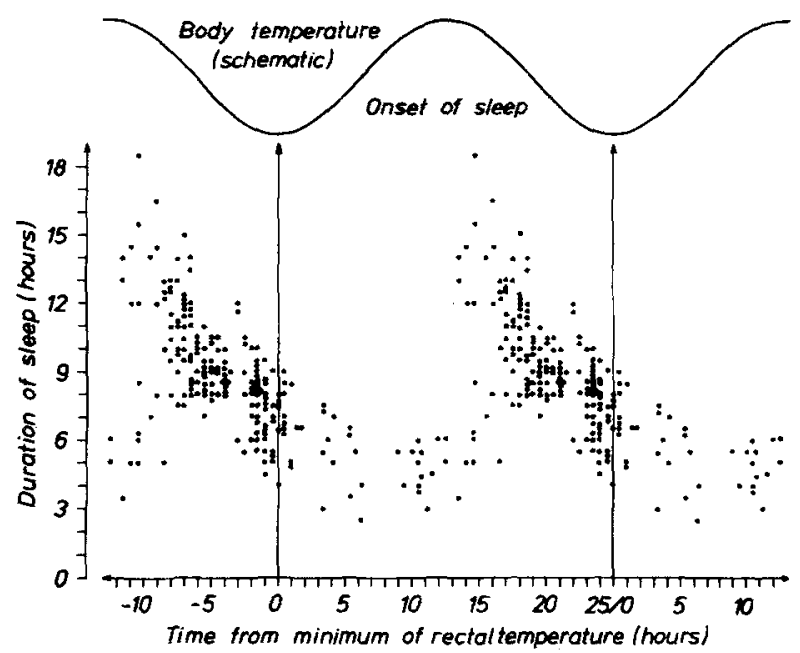

Fig. 5. Duration of sleep drawn with reference to the phase of the rhythm of rectal temperature. 206 sleep episodes from subjects with internal desynchronization. Double plot

sleep, and is shortest when onset of sleep coincides with increasing temperatures.

The dependence of sleep on the rhythm of body temperature as indicated in Fig. 5 suggests that sleep patterns can be influenced by manipulating the phase-relationship between the sleep-wake cycle and body temperature. This can be done by means of artificial zeitgebers which entrain the human circadian system (Aschoff et al. 1969). Entrainment to an artificially shortened "day" results in a phase delay of the circadian system, and entrainment to a lengthened "day" in a phase advance. As has been shown earlier (Wever 1972), within this range of entrainment the sleep-wake cycle and the rhythm of rectal temperature change their mutual phaserelationship in a systematic manner. As a consequence of these changes in phase, together with the interdependencies illustrated in Fig. 5, sleep characteristics can be expected to be different in shortened and lengthened days. This view is

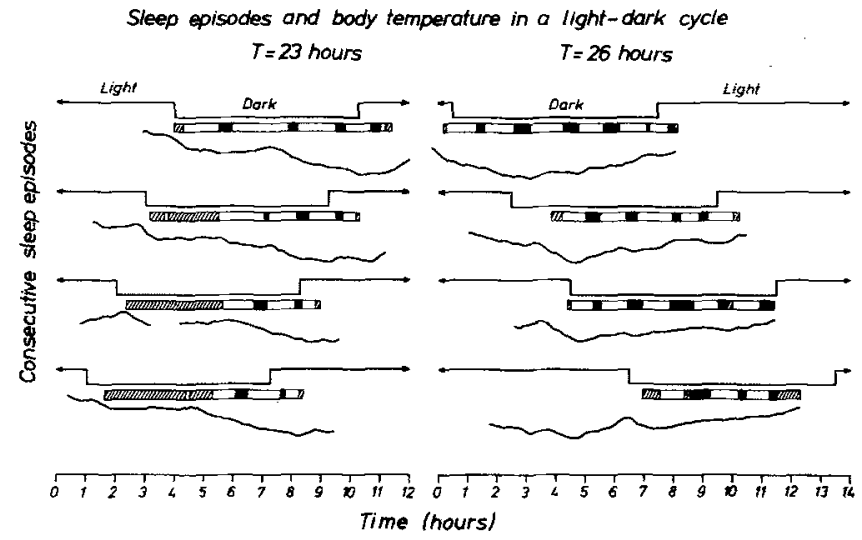

Fig. 6. Records of sleep (horizontal bars) and of rectal temperature taken twice in four consecutive nights from a subject entrained either by short or long light-dark cycles ( $T=$ period of the cycle). In the bars: shaded area $=$ sleep latency; black area $=$ rapid eye movements $(R E M)$

supported by the results of a pilot study in which EEG recordings were taken from a subject entrained for 14 days to a $23-h$ day, and thereafter for 14 days to a 26 -h day. From both conditions, the recordings of 4 nights are reproduced in Fig. 6. Although in the short as well as in the long days sleep was confined more or less to the dark hours of the light-dark cycle, the sleep patterns differed in the two conditions. In the short days, the subject went to bed at or shortly after the maximum of rectal temperature, but did not fall asleep until several hours later. Furthermore, the subject overslept the end of dark time, and its sleep episodes ended at about the minimum of temperature. Contrary to this, the subject in the long day went to bed several hours after the maximum and often at or even after the minimum of rectal temperature, had short sleep latencies, and was sometimes awake before the end of dark time. Similarly to the difference in sleep latency, REM latency was, on the average, longer in the short day than 
Table 1. Sleep characteristics (averaged from $n$ days) of a subject entrained by artificial light-dark cycles with an initial period $(T)$ of $23 \mathrm{~h}$, and then of $26 \mathrm{~h}$. REM: Sleep stage (rapid eye movements)

\begin{tabular}{lcc}
\hline & $\begin{array}{l}T=23 \mathrm{~h} \\
(n=13)\end{array}$ & $\begin{array}{l}T=26 \mathrm{~h} \\
(n=8)\end{array}$ \\
\hline Duration of bedrest (h) & $6.38 \pm 0.88$ & $5.61 \pm 1.62$ \\
Duration of sleep episode (h) & $5.25 \pm 1.60$ & $4.96 \pm 1.81$ \\
Sleep latency (h) & $1.11 \pm 1.60$ & $0.32 \pm 0.21$ \\
REM latency (min) & $72.8 \pm 23.3$ & $66.8 \pm 13.3$ \\
Duration of first REM (min) & $9.0 \pm 6.9$ & $13.0 \pm 9.9$ \\
\hline
\end{tabular}

in the long day (cf. Table 1; the data are the means of 13 sleep episodes in the short day, but only of 8 episodes in the long day because transients had to be omitted after the abrupt change from $T=23$ to $T=26 \mathrm{~h}$ ). In other words: a phase delay of the temperature rhythm in the short days was accompanied by difficulties of the subject to fall asleep, and a phase advance of the temperature rhythm in the long days was accompanied by early awakenings.

\section{Discussion}

Effects of wakefulness and sleep, or of activity and rest, on body temperature are well documented. Rectal temperature usually decreases whenever a subject changes from an upright to a horizontal position (Aschoff 1944; Kleitman and Doktorsky 1933) or when he falls asleep, and temperature increases after awakening or during activity (Aschoff 1970; Heller 1977). It is mainly due to these "masking effects" that the range of oscillation ( = difference between daily maxima and minima of temperature) is about $25 \%$ smaller during continuous bedrest as compared to conditions with modest activities during daytime (Aschoff and Wever 1980), and 45\% smaller during sleep deprivation (Aschoff 1981a).

In contrast to the many findings concerning the influence .of sleep on body temperature, little attention has been given to the effects of deep body temperature on sleep. An expecially informative opportunity to study this kind of interaction is provided by the phenomenon of internal desynchronization. As demonstrated in Figs. 4 and 5, the temperature rhythm influences the probability to fall asleep as well as the duration of a sleep episode. It should be noted, that in both these figures data are summarized from the two types of experiments in which subjects were either exposed to continuous illumination (LL) or could turn on and off the lights in the isolation unit at will (LD). The combined analysis is justified because there are no differences in the results between the two conditions: the mean duration of sleep episodes was $8.79 \pm 2.82 \mathrm{~h}$ in $\operatorname{LL}(n=87)$ and $8.62 \pm 2.10 \mathrm{~h}$ in $\mathrm{LD}(n=119)$. These figures are not statistically different from those obtained during internal synchronization: $8.11 \pm 1.61$ in LL $(n=110)$ and $8.51 \pm 1.53 \mathrm{~h}$ in $\mathrm{LD}(n=95)$. The desynchronized rhythms differ, however, from the synchronized rhythms in that the standard deviation of the mean duration of sleep is $40-85 \%$ larger.

A dependence of duration of sleep on the daily course of body temperature was suggested by Zulley (1976) and indicated by data presented at the first European Congress on Sleep Research in 1978 (Zulley and Schulz 1980). The first full documentation of the relationship between sleep duration and phase of the temperature rhythm was given in the thesis of Czeisler (1978). In a later publication, Czeisler and coworkers (1980a) presented a more detailed analysis of data obtained from five subjects who were internally desynchronized. According to these authors, the duration of a sleep episode is longest when sleep begins $12-14 \mathrm{~h}$ before the temperature minimum. This interval is about $2 \mathrm{~h}$ longer than that indicated in Fig. 5. This difference is likely to be explained by the fact that Czeisler and coworkers have plotted the sleep values in reference to an "educed waveform" of body temperature while the data shown in Fig. 5 are plotted in reference to the temperature minimum as computed in each cycle separately. It is probably for the same reason that, in another analysis of their data Czeisler and coworkers (1980b) report a maximum of bedrest onsets during the $2 \mathrm{~h}$ after the "educed" temperature minimum, while in Fig. 4 a maximum of sleep onsets is indicated shortly before the (actual) temperature minimum. A secondary maximum of bedrest (sleep) onset is indicated in both sets of data, but with different relationships to the rhythm of body temperature. This bimodal distribution of sleep onsets during internal desynchronization is not yet fully understood. The one maximum just before the temperature minimum is similar to that seen during internal synchronization (compare the left and right histograms in Fig. 4). The second maximum of sleep onsets observed during desynchronization coincides with about that phase of the temperature rhythm at which subjects prefer to fall asleep when they are synchronized to $24 \mathrm{~h}$.

The correlation between duration of sleep and phase of the temperature rhythm should, of course, not be considered as being due to a direct effect of temperature on sleep. The findings discussed here rather indicate that the two systems controlling the sleep-wake cycle and the circadian rhythms of autonomic functions continue to interact during internal desynchronization, i.e. when the coupling forces become to weak to sustain mutual synchronization. This interaction during "relative coordination" was first documented in freerunning rhythms with internal desynchronization by the continuous modulation of the range of oscillation in temperature (cf. Fig. 5 in Aschoff et al. 1967a). A similar dependence of temperature on the phase of the sleep-wake cycle has been observed in the 10 desynchronized subjects whose data are discussed here; details of the analysis are published elsewhere (Aschoff 1981b; Zulley and Wever 1982).

Under normal conditions, i.e. in healthy subjects entrained to $24 \mathrm{~h}$, only minor variations occur in the phaserelationship between the sleep-wake cycle and the rhythm of rectal temperature (Aschoff and Wever 1980). Hence, no drastic effects can be observed on the sleep pattern from changes in the rhythm of body temperature. Such effects are, however, to be expected if the phase of the temperature rhythm becomes more variable. In recent years, hypotheses have been advanced that certain psychiatric illnesses might be related to or the consequence of such disorders in the circadian time structure (Aschoff 1981 c; Pflug and Martin 1980). In particular, several authors claim that manic depressives might be characterized by a phase-advance of the rhythm in body temperature and other autonomic functions (Kripke 1979; Wehr et al. 1979, 1980). If this is correct, it might be expected that sleep patterns similar to those observed during depression could be induced in a subject by artificially advancing his temperature rhythm. It is under those aspects that the pilot study described above had been performed. The results agree with the assumption in so far as 
in the artificially lengthened day (which results in a phase advance of the temperature rhythm) short REM latencies and early awakenings were observed, i.e. sleep patterns characteristic for a depressed patient. It is of equal interest that the opposite situation, i.e. the entrainment to an artificially shortened day with its concomitant phase delay of the temperature rhythm, results in difficulties to fall asleep, a sleep pattern which has been found in neurotic subjects (Kiloh and Garside 1963).

\section{References}

Aschoff J (1944) Über die Interferenz temperaturregulatorischer und kreislaufregulatorischer Vorgänge in den Extremitäten des Menschen. Pflügers Arch Ges Physiol 248:197-207

Aschoff J (1970) Circadian rhythms of activity and of body temperature. In: Hardy JD, Gagge AP, Stolwijk JAJ (eds) Physiological and behavioral temperature regulation. $\mathrm{Ch} \mathrm{C}$ Thomas Publ, Springfield Illinois, pp 905-919

Aschoff J (1981 a) Circadian rhythms: interference with an dependence on work-rest schedules. In: Johnson LC, Tepas DI, Colquhoun WP, Colligan MJ (eds) Biological rhythms and shift work. Advances in sleep research, vol 7. Spectrum Publications, New York (in press)

Aschoff J (1981 b) Circadian system properties. In: Obal F, Benedek K (eds) Advances in physiological sciences, vol 18. Environmental physiology. Akademiai Kiadé, Budapest, pp 1-17

Aschoff J (1981 c) Disorders of the circadian system as discussed in psychiatric research. In: Wehr TA, Goodwin FK (eds) Circadian rhythms in psychiatry. Boxwood Press, Neuroscience Series, Los Angeles (in press)

Aschoff J, Wever R (1980) Über Reproduzierbarkeit circadianer Rhythmen beim Menschen. Klin Wochenschr 58:323-335

Aschoff J, Gerecke U, Wever R (1967a) Desynchronization of human circadian rhythms. Jpn J Physiol 17:450 - 457

Aschoff J, Gerecke U, Wever R (1967b) Phasenbeziehungen zwischen den circadianen Perioden der Aktivität und der Kerntemperatur beim Menschen. Pflügers Arch 295:173-183

Aschoff J, Pöppel E, Wever R (1969) Circadiane Periodik des Menschen unter dem Einfluß von Licht-Dunkel-Wechseln unterschiedlicher Periode. Pflügers Arch 306:58-70

Czeisler CA (1978) Human circadian physiology: internal organization of temperature, sleep-wake, and neuroendocrine rhythms monitored in an environment free of time cues. Ph D Thesis, Stanford University
Czeisler CA, Weitzman ED, Moore-Ede MC, Zimmerman JC, Knauer RS (1980a) Human sleep: Its duration and organization depend on its circadian phase. Science 210:1264-1267

Czeisler CA, Zimmerman JC, Ronda JM, Moore-Ede MC, Weitzman ED (1980 b) Timing of REM sleep is coupled to the circadian rhythm of body temperature in man. Sleep 2:329-346

Heller HC (1977) Thermoregulation during sleep hibernation. In: Robertshaw D (ed) International review of physiology: Environmental physiology II, vol 15. University Park Press, Baltimore, pp 179-188

Kiloh LG, Garside RF (1963) The independence of neurotic depression and endogenous depression. Br J Psychiat 109:451-463

Kleitman N, Doktorsky A (1933) The effects of the position of the body and of sleep on rectal temperature in man. Am J Physiol 104: $340-343$

Kripke DF, Mullaney DJ, Atkinson ML, Huey LY, Hubbard B (1979) Circadian rhythm phases in affective illnesses. Chronobiologia $6: 365-375$

Pflug B, Martin W (1980) Analyse circadianer Temperaturgänge bei endogener Depression. Arch Psychiat Nervenkr 229:127-143

Wehr ThA, Muscetolla G, Goodwin FK (1980) Urinary 2-methoxy-4hydroxyphenylglycol circadian rhythm. Arch Gen Psychiatry 37: $257-263$

Wehr ThA, Wirz-Justice A, Goodwin FK, Duncan W, Gillin JCh (1979) Phase advance of the circadian sleep-wake cycle as an antidepressant. Science 206:710-713

Wever R (1972) Mutual relations between different physiological functions in circadian rhythms in man. J Interdiscipl Cycle Res 3: $253-265$

Wever R (1979) The circadian system of man. Springer, Berlin Heidelberg New York

Zulley J (1976) Schlaf und Temperatur unter freilaufenden Bedingungen. In: Bericht über den 30. Kongress der dtsch Ges für Psychol. Hogrefe, Göttingen, pp 398-399

Zulley J, Schulz H (1980) Sleep and body temperature in free-running sleep-wake cycles. In: Sleep 1978. Fourth European Congress on Sleep Research, Tirgu Mures. S Karger, Basel, pp 341-344

Zulley J, Wever R (1982) Interaction between the sleep-wake cycle and the rhythm of rectal temperature. In: Aschoff J, Daan S, Groos G (eds) Vertebrate circadian systems: structure and physiology. Springer, New York Heidelberg Berlin (in press)

Received July 28/Accepted August 17, 1981 